\title{
Effect of seismic operations on cetaceans sightings off-shore Akwa Ibom State, south-south, Nigeria
}

\author{
Olakunle G. WOLE* and Emmanuel F. MYADE \\ Nigerian Institute for Oceanography and Marine Research, NO.3, Wilmot Point, \\ Victoria Island Lagos, Nigeria. \\ *Corresponding author, E-mail: gideolak@yahoo.com; Tel: +234- 8055-306-942
}

\begin{abstract}
The possible behavioral and physical problems involving cetaceans and marine seismic surveys have attracted the interest and concern of several authors. However, studies on cetaceans frequenting Nigerian waters have not been detailed in literature. This research work is appropriately driven by these requirements. Opportunistic data was collected on board six different marine vessels belonging to ExxonMobil. Data collected were analyzed using descriptive statistics, t-test and ANOVA at $\mathrm{p}=0.05$. A total of 8,327 hours 36 minutes observation effort was accomplished during twenty-six months, representing almost $800 \mathrm{~km}^{2}$ of coverage. Two hundred and eighty-three (283) sightings were recorded comprising of $189(66.78 \%)$ sightings of whales and $94(33.22 \%)$ sightings of dolphins. Four species of cetaceans were identified, bottlenose dolphins (Tursiops truncatus) were the most abundant followed by pantropical spotted dolphins (Stenella attenuata). These two species occurred throughout the sampling months, while the predominant whales specie were the humpback whale (Megaptera novaeangliae) and killer whales (Orcinus orca) which seem to be present in just a part of the year. Whales were sighted more when the guns were active. Conversely, less of the dolphins were sighted while the guns were active. There were significant differences $(\mathrm{P}=0.05)$ regarding the air-gun operational state between the number of whales and dolphins sightings. The result suggests that swimming behavior was dependent of air-gun operational state.
\end{abstract}

(C) 2014 International Formulae Group. All rights reserved.

Keywords: Cetaceans, seismic survey, Sightings, Akwa Ibom state, south-south Nigeria.

\section{INTRODUCTION}

Over the course of the last couple of decades, scientists and conservationists have become increasingly aware of threats to biodiversity that are diffused and hard to assess but are, nonetheless, of great concern. Three examples are climate change, chemical pollution and marine noise pollution (Bluhn et al., 2007). Of the three, chemical pollution has received the greatest attention and response mechanisms are already enshrined in a host of national and international law. However, by contrast, noise pollution in the marine environment is still an emerging, but undoubtedly serious, concern. Its implications are less well understood than other global threats but like chemical pollution, it is usually largely undetectable to everyone but the specialist. It is also difficult to comprehend, particularly for those that live above the sea surface and do not readily appreciate the profound importance of sound 
to marine animals, particularly the cetaceans in the oceans (Bailey et al., 2006).

Cetaceans are marine mammals that are primarily ocean dwelling or depend on the ocean for their food and survival. Several familiar coastal species such as dolphins and whales have received far less attention in these waters. Yet these and other inshore species arguably form a significant component of the marine ecosystem, and may be of considerable tourism and conservation priority in this respect (Clark et al., 2006). Cetaceans spend their entire lives in the water and most of the times ( $>90 \%$ for most species) entirely submerged below the surface, when at surface, cetaceans bodies are almost entirely below the water surface, with only the blowhole exposed to allow breathing. This makes cetaceans more difficult to locate visually and exposes them to underwater noise both natural and anthropogenic essentially $100 \%$ of the time because their ears are nearly always below the water surface (Angliss et al., 2006). There is now a world-wide trend towards increasing oil exploration in deeper waters, Nigeria inclusive, and this has brought with it an increased potential for conflict between those species of cetacean thought to be most vulnerable to seismic pulses. Cetaceans may be especially sensitive to anthropogenic noise because some species of toothed whales have developed a special sense called echolocation that allows them to hunt and gather information about their environment in turbid and deep water where no light penetrates (Robinson et al., 2007b). They send out a sound into the water and then use the returning echo to identify the objects that have reflected the sound. The differences in the returning echo provide the animal with information about the size, shape, orientation, direction, speed, and composition of the object or landscape (Madsen et al., 2004). Communication is a behavior by one individual which causes a change in behavior or state of another individual, the receiver, through conveying information (Alcock, 2005). Cetaceans use sound to communicate information about the location and identity of individuals or groups, reproductive status, food sources, predation risk, and dominance (Madsen et al., 2005). For example, humpback whale males compete with other males through complex songs that can last for several hours, and females choose between males based on these vocalizations ( Weir et al., 2007). The ability of cetaceans to communicate, navigate, and echolocate can be compromised by human noise. Noise is a disturbance, usually random and persistent, that obscures or reduces the clarity of a signal (Richardson et al., 1995a). The ocean is naturally noisy, which would seem to present problems for marine mammals using sound, however, they are well-adapted to natural levels of ambient noise (NRC, 2003). However, masking can occur, which is the blocking of the perception stimulus, resulting from the presence of another stimulus in the same range. Marine seismic surveys are some of the harshest anthropogenic noises cetaceans are subjected to (Gordon et al., 2003). Seismic surveys use reflected seismic waves to produce images of the Earth's subsurface (Gordon et al., 2003). The method requires a controlled seismic source of energy, such as dynamite or a specialized air gun. By noting the time it takes for a reflection to arrive at a receiver, it is possible to estimate the depth of the feature that generated the reflection. In this way, reflection seismology is similar to echolocation (Richardson et al., 1995b). The reactions of cetaceans to seismic surveys have included surprise, fright, stress, and avoidance. Mysticeti and Odontocetes have also shown changes in behavior and vocalization patterns such as disruption of foraging, avoidance of particular areas, altered dive and respiratory patterns, and disruption of mating systems (Gordon et al., 2003). Past studies on the reactions of cetaceans to noise have shown widely divergent responses depending on the individual, age, sex, and the activity in which the animals were engaged (Koblitz et al., 2012). 
There have been few studies detailing the long-term effects of disturbance on cetaceans. Morton and Symonds (2002), found that killer whale displacement occurred for several years from an introduction of noise into their environment. Beluga whales will flee from approaching ice-breaking vessels, traveling up to $80 \mathrm{~km}$ away from productive and feeding areas, and remain displaced for several days (Erbe and Farmer 2000). A study conducted in Australia found that long-term disturbance negatively affected populations of bottlenose dolphins (Bejder et al., 2006). Cetacean-watching tourism has increased over the years and this has lead to a decline in dolphin abundance in this area. These cases show examples of animals not being able to cope in a changing environment and suggest that cetaceans may not be adjusting to longterm anthropogenic noises (Kyln et al., 2010).

Determining average behavioral reactions of cetaceans to anthropogenic noise is complex because there is such high variability in terms of behavioral response between species and even between individuals within a species (NRC, 2003). Varied responses, ranging from attraction of dolphins to the bow of a ship to long-term displacement, exploratory behavior in others or habitat avoidance by harbor porpoises or have been documented (Culik et al., 2001). Some sounds may not cause any observable responses, and while other sounds may cause subtle changes in diving, surfacing, or vocalization patterns, these changes in behavior are not necessarily a cause for concern if they are temporary or do not cause the animal to leave an area important to their survival (such as breeding or foraging areas). For example, Pilot whales respond vocally to military sonar pulses from a considerable range over long periods of time (Koschinski et al., 2003). These long-term induced responses are not necessarily deleterious, but they are unlikely to be adaptive (Kloepper et al., 2010).

Cetaceans being top predators play a significant role in the balance of the marine ecosystem. Consequently, any perceived threat to their survival requires a scientific investigation for the purpose helping policy makers to make informed decisions. The underlying objective of the research work was to establish and document the effect/relationship between seismic operations and sighting of cetacean species in Nigerian coastal waters. The study focuses on the coastal cetaceans frequenting the Nigerian coastal waters so as to provide baseline scientific data for the adoption of long-term management measures and conservation strategies for their protection.

\section{MATERIALS AND METHODS}

\section{Study area}

The study area covers about $800 \mathrm{~km}^{2}$ located Akwa Ibom State ( $3^{\circ} 50^{\prime} \mathrm{N} \& 7^{0} 10^{\prime} \mathrm{E}$ to $\left.4^{\circ} 50^{\prime} \mathrm{N} \& 8^{\circ} 40^{\prime} \mathrm{E}\right)$ in the oil rich southsouth region of the Niger delta area of Nigeria. The site is delineated OML (oil mining license). It consists of OML 67, 68, 69 and 70 belonging to ExxonMobil producing Nigeria.

This study was based on the results of marine mammal observations during seismic surveys on board six different marine vessels belonging to ExxonMobil whose primary objective was to conduct seismic operations. Airguns were towed at 5 knots at a depth of 5$10 \mathrm{~m}$ while shots were fired at approximately 10 seconds along transect lines.3-D technology was employed. The overall observation effort was 8,327 hours 36 minutes accomplished over a period of 26 months (Nov.2007-Dec.2009) almost covering $800 \mathrm{~km}^{2}$ representing OMLs $67,68,69$ and 70 belonging to ExxonMobil Producing Nigeria in Akwa Ibom State, South-south of Nigeria. The presence of cetaceans was sought for before a survey line was started, and the start was delayed by at least 20 minutes if cetaceans are within 500 metres.

Marine mammals were monitored during the seismic operations through visual survey by on board marine mammal observers 
from the highest vantage points aboard (14.5m a.w.1.). Species occurrence and behavior were recorded on "Biota Records and Occurrence Forms" designed by JNCC (Joint Nature Conservation Committee). The information presented on the forms was as follows: Boat (identification, activity, geographical position and direction); Seismic survey [date, time, depth, sea state, weather conditions visibility and wind direction and strength - and observer's name]; Animal [species, anatomical description, number of specimens (total, adult and calves), identification level (definite, probable and possible), behavior (swimming, feeding, courting, stationary, playing, other), air-gun state (turned on or off) and other comments. There were no marine mammals monitoring when visibility was poor because it was difficult to observe marine mammals.

The number of marine mammal observers, their degree of experience and level of monitoring effort varied throughout the seismic surveys. Three of the observers with more than ten years of experience were classified in this study as an "Expert" while four of the observers with more than five but less than ten years classified as "Capable" and one "Beginner" was contracted. This observer (Beginner) underwent a training program that included sighting methodology, safety procedures and the most likely species to be seen in the area. The training program lasted three days, after which the observer was able to remain active in the project until its conclusion. All the observers were marine science professionals with M.Sc. academic qualification and they all participated in the same training program.

\section{Statistical analysis}

Information from the Biota Records and Occurrence Forms was analyzed using descriptive statistics, t-test ANOVA and Kruskal-Wallis non-parametric test relating sightings of marine mammals to the hour class interval, at $\mathrm{p}=0.05$.

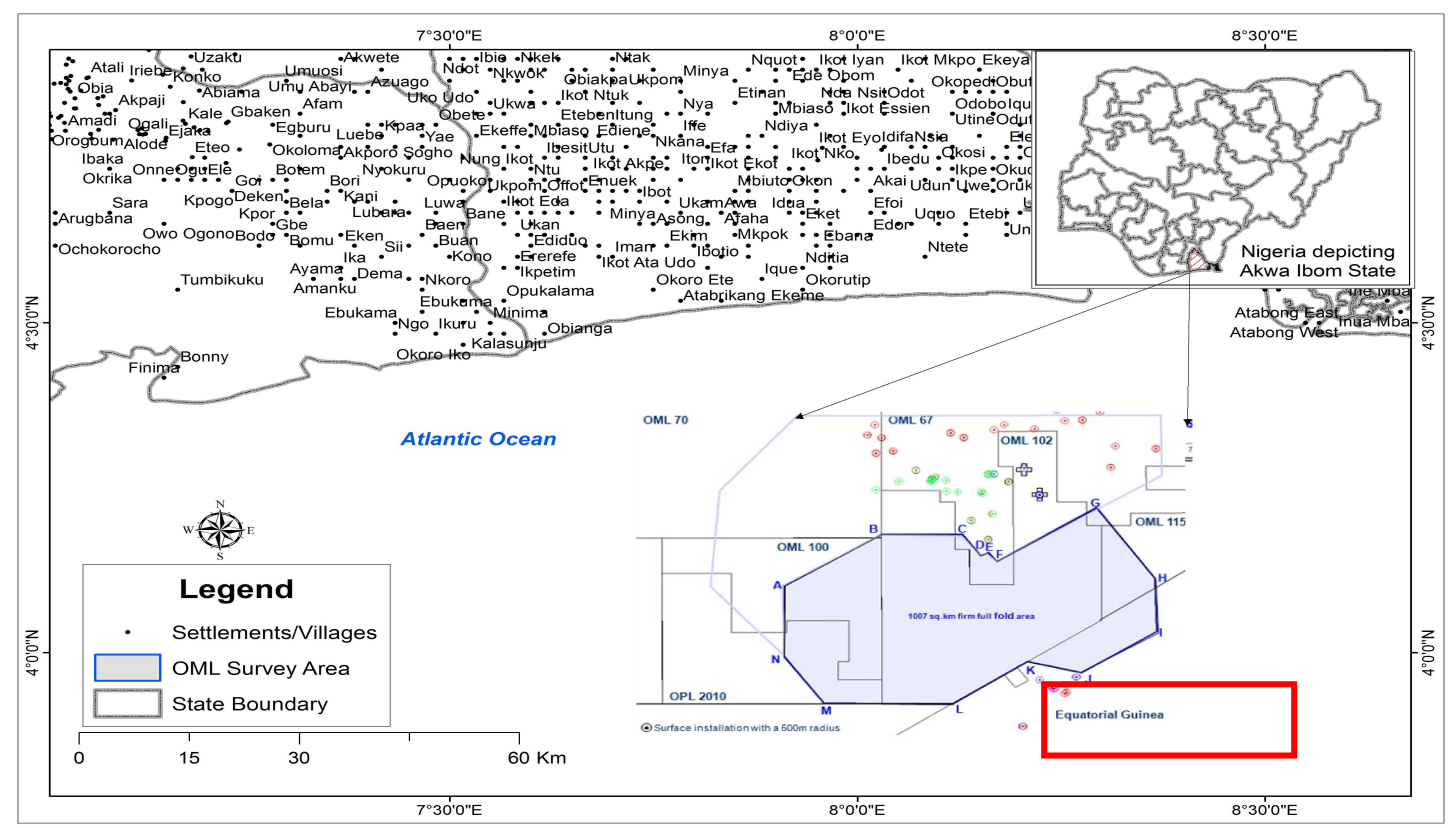

Figure 1: Study site with Nigeria insert. 


\section{RESULTS}

A total of 8,327 hours 36 minutes of marine mammal monitoring was carried out during 11,506 hours 56 minutes of seismic surveys. This marine mammal monitoring corresponded to $72.4 \%$ of the total duration of the seismic surveys and was not synchronized with the operation of the air-guns. An average watch time of 287 hours 9 minutes and 31 seconds was recorded per month. The total number of hours spent per month is presented in Figure 2. Average MMO watch time per day was 9 hour 13 minutes with 11 hours 9 minutes being the highest and the lowest was about 2 hours 5 minutes as dictated by the weather condition, seismic production operations and vessel activities per day. No monitoring was carried out on some days due to crew change.

The marine mammal monitoring programs recorded 283 sightings of 339 specimens of whales and 1342 specimen of dolphins, including Megaptera novaeangliae (the humpback whale), killer whales (Orcinus orca) which seem to be present in just a part of a year, Tursiops truncatus (Bottlenose dolphin), Delphinus delphis (Common dolphin), Sousa teuszii (Atlantic hump-backed dolphin) and Stenella attenata (Stenella attenuate). The most abundant species were Bottlenose dolphin (36\%), Stenella attenuate (27\%), Common dolphin (23\%) and Humpback whale (18\%) Figure 3. Sightings peaked during July and August.

The relationship between the periods the seismic guns were shooting and the number of marine mammals sighted was analyzed and is as shown in Figure 3. Of the total whale sightings, $73 \%$ was recorded while the guns were shooting and $27 \%$ recorded while the guns were inactive. Conversely, the number of sightings recorded for the dolphins while the guns were shooting was $35 \%$ and $65 \%$ when the guns were inactive. Whales were sighted more when the guns were active but they were sighted at safe distances (greater than 500 meters) away from the guns. Less of the dolphins were sighted while the guns were active and those sighted were also at safe distance away from the guns except on two occasions when shooting were stopped or delayed for the animals to move to safe distance away from the guns. Records of sighting showed that a number of calves (juveniles) were sighted during the reporting period and the number of juveniles sighted for the dolphins were more than the adults. Among the total individual whales (339) recorded, $83 \%$ were adults and $17 \%$ were juveniles while more of the juveniles (54\%) than the adults $(46 \%)$ of the total individual dolphins (1342) were recorded. Though operation Licenses demanded that marine mammal monitoring should be carried out during the entire period of air-gun activity Nevertheless, there was no night monitoring due to the risk of accident with the observers and no marine mammal was recorded during these periods of darkness. All sightings of marine mammals occurred between 06:00 and 18:00 hours, which correspond to the daylight period in south-south Nigeria. The KruskalWallis non-parametric test $(H=17.21)$ relating sightings of marine mammals to the hour class interval was highly significant $(\mathrm{p}=0.05)$. There was a significantly higher probability of observing marine mammals between 0800 and 1600 hours i.e. during daylight hours.

The observed behaviors were: swimming $(81.2 \%)$, playing (12.3\%), feeding $(3.5 \%)$ and stationary (2.5\%) (Figure 6). Behavior observations only exceeded 10 minutes when the marine mammals were seen within a distance of 500 meters from the Gunboat, whilst observations longer than 15 minutes were never recorded by observers during the periods when air-guns were "switched on", only swimming (61\%) and playing $(10.5 \%)$ behaviors were recorded. The frequency of swimming behavior was greater when the air-guns were "switched off" $(83.3 \%)$, however the Mann-Whitney statistical test showed that this difference regarding the air-gun operational state was not statistically significant $[U=16.50 ; Z(U)=1.022$; $\mathrm{p}=0.05]$. This result suggests that swimming behavior was independent of air-gun operational state. 


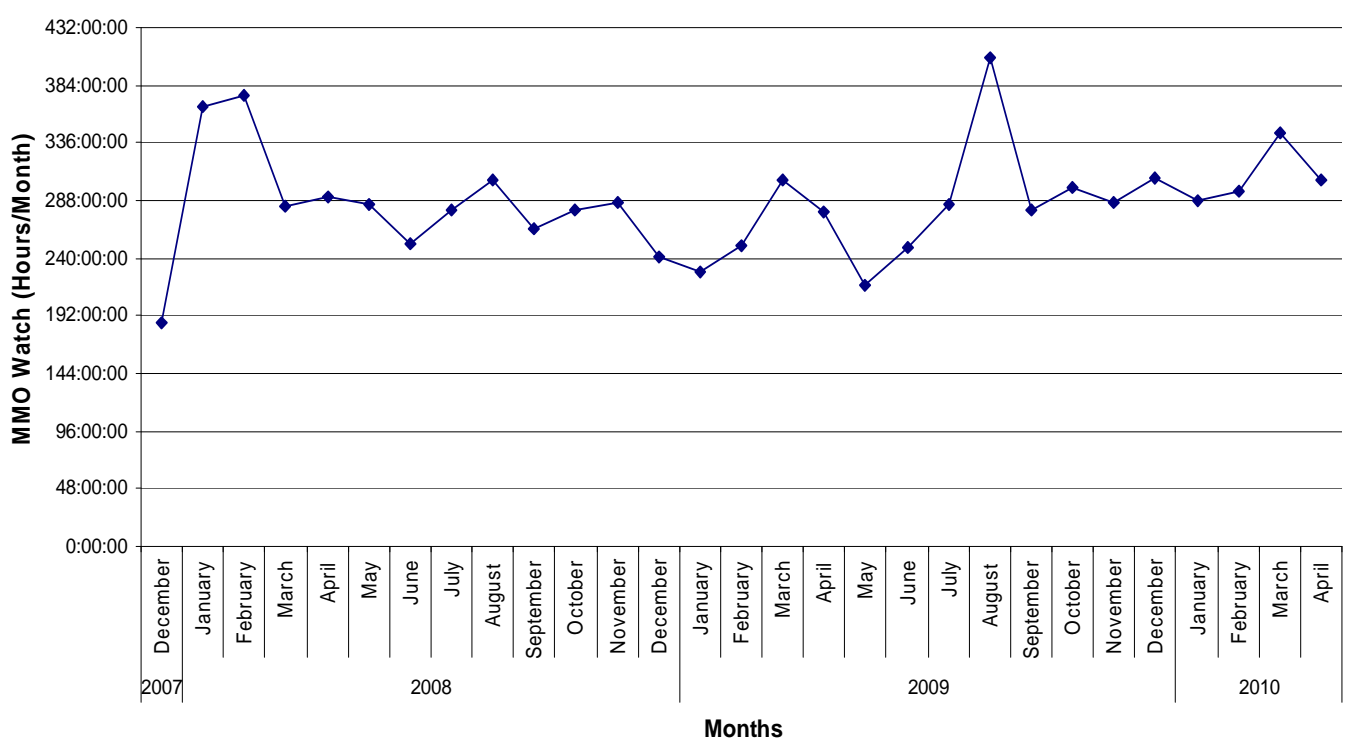

Figure 2: Observation hours per months.

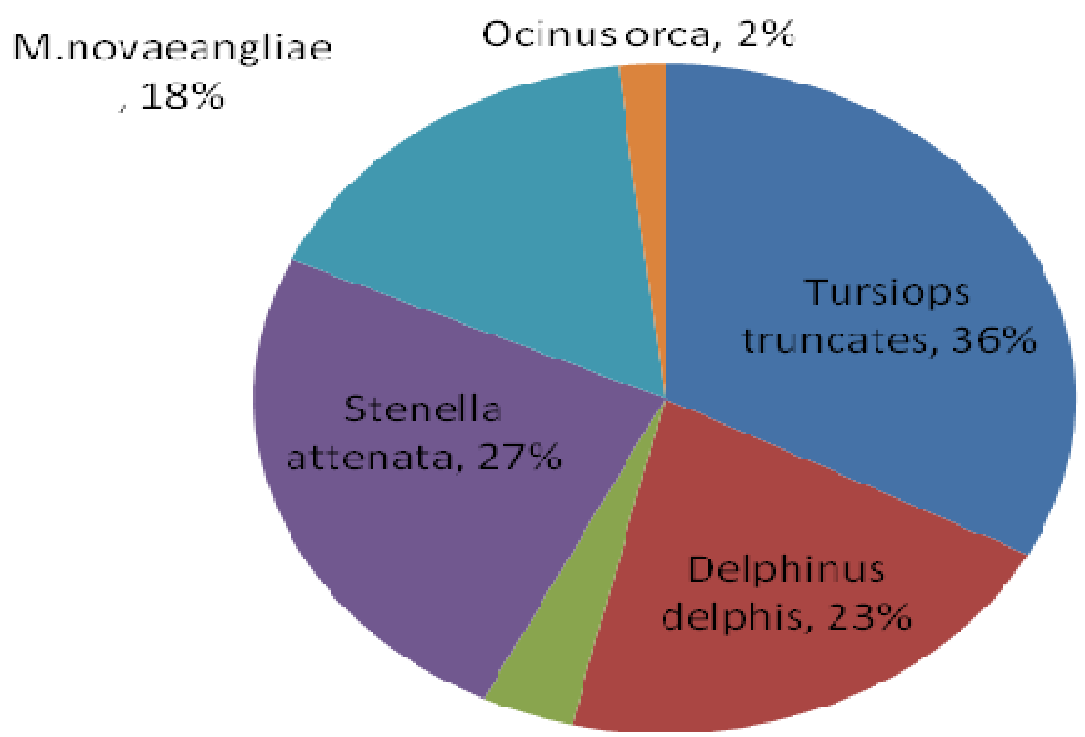

Sousa teuzii, $4 \%$

Figure 3: Species composition of cetaceans. 


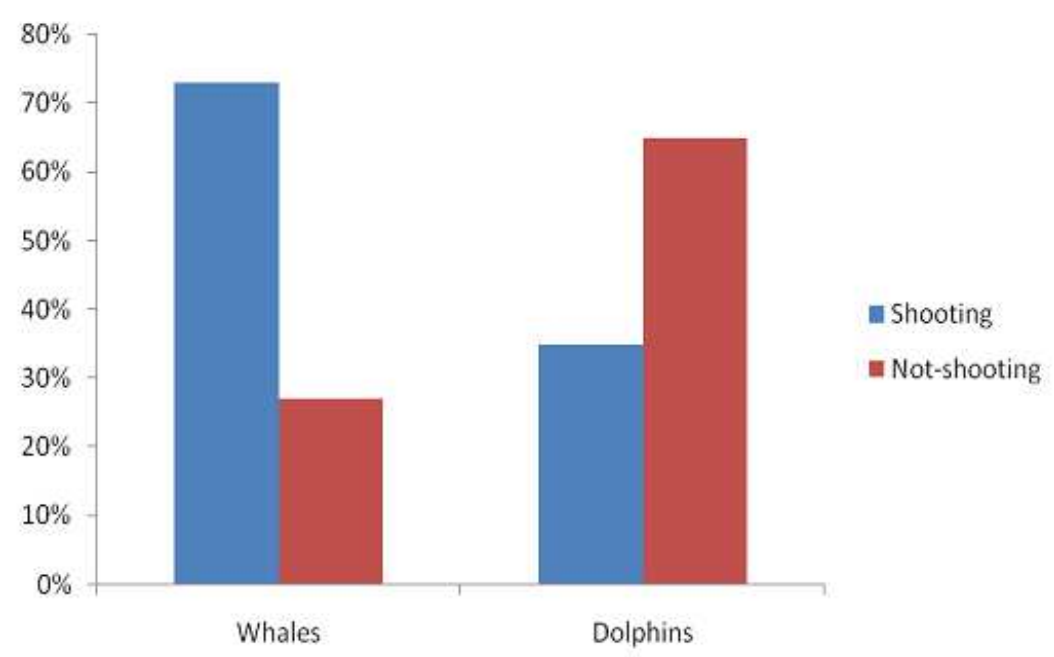

Figure 4: Sighting of Cetaceans in relation to seismic activities.

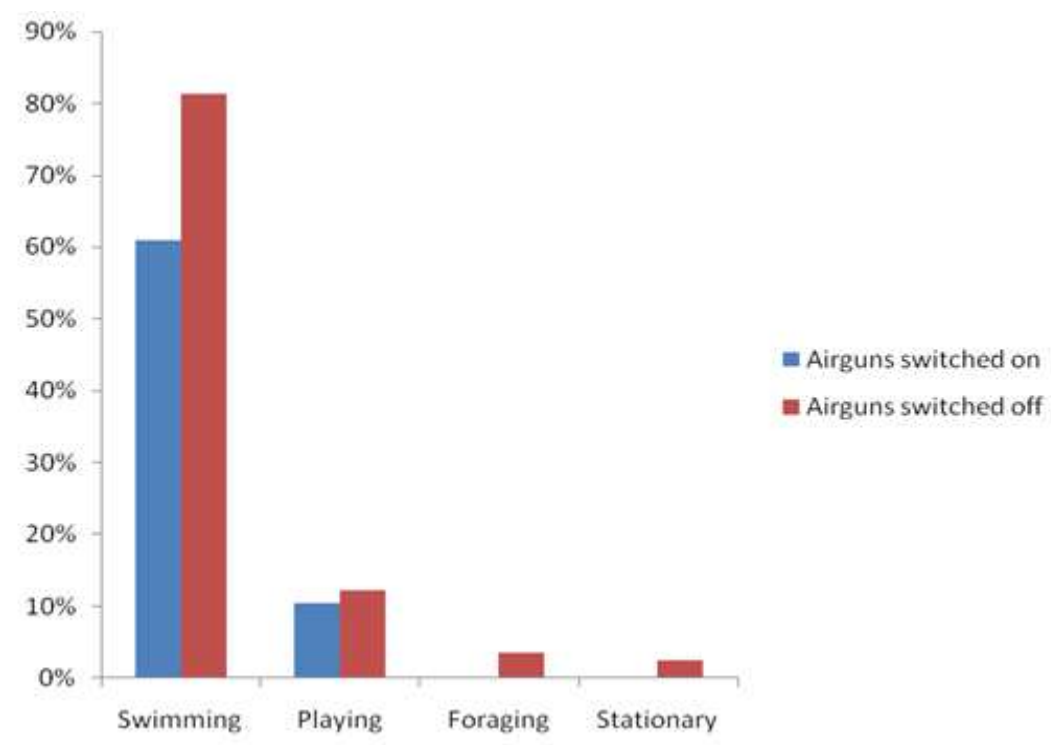

Figure 5: Observed behaviours of Cetaceans when Air guns were "On” or" Off.

\section{DISCUSSION}

The result is an indication that the project area is part of the breeding grounds for marine mammals. The result of this observation also shows that despite the seismic operation in the area, the mammals still migrate to this area for breeding. More frequent sightings of whales seen when shooting could reflect the greater ease of detecting cetaceans in the calmer weather conditions necessary for shooting. Although numbers of cetaceans declined after August, 
this was not thought to be a result of prolonged seismic activity. Any disturbance seemed to be only temporary, with cetaceans rapidly appearing in the survey areas between periods of shooting.

In Nigeria waters, the areas of most intensive oil and gas activity are the Niger delta area located in the south- south region. The study area has been the subject of considerable oil and gas activities for many years, and the area is also of great importance for a number of cetacean species as established by this study. Interpretation of behavioral responses of marine mammals during seismic surveys is complex and little studied. Nevertheless, quantitative behavioral studies are an important tool used to investigate potential human impacts on the marine environment (Leung and $\mathrm{Ng}$, 2003). It is also essential to observe and evaluate the methodologies used to investigate these potential human impacts.

The sampling methods used in this research could be classified as "incident sampling" because of the short duration of sightings when only the behavior presented at the instant of detection is recorded (Mann, 1999). Therefore, without previous experience and knowledge of the behavioral repertoire of the species exhibited during a seismic survey, it could be argued that it is not possible to infer an accurate response to human activity during that instantaneous observation.

Considering the above, we suggest that a sustained research effort should be instituted year in year out.

The results of this project have many important and wide-ranging applications and impacts. There has been increasing seismic activity in Nigerian waters for oil exploration. Relationship between seismic activities and marine mammals has been established in that the large noise generated by seismic guns can cause damage to auditory (hearing) system of the mammals thereby making them 'deaf' and consequently hampering their ability to navigate, communicate and/or feed (Gausland, 2003; McCauley et al., 2000). Hence, the need for adequate mitigating measures put in place during seismic operations to minimize the impact of seismic activity. The mammals may avoid breeding or feeding grounds as a result of being impacted upon by seismic activity. Most wildlife (including marine mammals) are classified as threatened and endangered (NEST, 1991). This work presents unique opportunities for understanding the mechanisms of adaptation by these upper tropic level marine predators in such a hot tropical environment. Additional benefits of this work also include the interests of comparing the social ecology and behavior of these cetaceans to other cetacean communities around the world in order to better understand how different factors, such as environmental conditions and food availability for example, may combine to shape the social structure and behavior in these species. A long-term analysis of data recorded between 2007 and 2010 has also shown that high numbers of neonate calves are recorded in the project area between the months of July and September. In fact, $65 \%$ of all dolphin schools recorded are found to have at least one calf in tow and these results give weight to the hypothesis that the study area constitutes an important nursery/calving ground for these cetacean population. Consequently, it is recommended with respect to these findings that exploration technology with low impact on these vulnerable fractions of the population must be adopted.

As long-lived mammals with low reproductive rates, clear assessments of the status of these animals require a long-term and ongoing research approach, and in this respect the current objectives of the research work form part of a monitoring program for the 
species. An equally important step for the development of effective conservation strategies for the whales and dolphins requires an understanding of oil exploration companies' perception of these animals, the threats they currently face and the perceived importance of these animals to the local economy. Such knowledge can be used to target effective environmental programmes in the areas of education, publicity and public relations. We recommend several lines of action to improve the effectiveness of marine mammal monitoring programs, starting with a review of the monitoring protocol, including observations before and/or after the seismic effort to allow analysis of changes in distribution. Other actions include revising the data collection forms focused mainly in the group behavior such as swimming speed, approach or avoidance behavior and abrupt changes in direction. A final important action is to establish a training program for more indigenous observers for these kinds of surveys, which would enable them to correctly identify species and behaviors. We feel that these recommendations would better prepare the marine mammal observers from host countries and greatly improve the protocol for monitoring marine mammals during marine seismic surveys. Even these analyses have been done on the scope of the monitoring of seismic survey impacts, its results and concepts could be extended to all monitoring programs of marine mammals developed on coastal zone contributing to its improvement.

We also recommend that different monitoring techniques (e.g. acoustic monitoring, aerial surveys and telemetry) should be conducted by researchers independent of the Geophysical Companies regarding the effects of seismic surveys on the density, distribution and behavior of cetaceans and manatees. This independent acoustic monitoring should be conducted mainly during seismic surveys carried out at night or when visibility conditions are not favorable.

Finally, we strongly recommend that a comprehensive assessment and compilation should be made of all marine mammal monitoring programs conducted during seismic surveys in Nigerian waters since when oil and gas exploration began till date. This more comprehensive analysis would further support the preparation of a protocol and assist in the licensing and fiscal processes for petroleum exploration in marine areas of Nigeria. The adoption of these recommendations will increase knowledge of the occurrence and distribution of marine mammals on the Nigerian coastal waters, as well as help address concerns regarding the effects of seismic surveys on these animals.

\section{Conclusion}

Protection for Nigerian cetaceans could be improved if internationally accepted guidelines were strictly adhered to and tightened up to include the use of passive acoustic monitoring (PAM) on all surveys, and a requirement that air guns be shut down if cetaceans are sighted when the air guns are firing as there is currently no mitigation for animals that may approach the sound source once firing of the air guns is underway. Compliance with the Habitats Directive is imperative since the effects of seismic activity could be shown to be causing the deterioration and destruction of breeding sites or resting places. Strategic Environmental Assessments (SEA) been undertaken for oil and gas activities in different areas of Nigerian seas must identify particular areas too sensitive to damage and relevant government agencies must enforce internationally acceptable guidelines that could protect this endangered animal. 


\section{ACKNOWLEDGEMENTS}

We wish to thank the management of ExxonMobil producing unlimited (Nigeria) for providing the platform which enabled us to collect these data. We wish to thank ALLOLIS GEOSCIENCES Lagos for giving us opportunity to be part of this project. Our gratitude goes to the management of NIOMR and our colleagues in Marine Biology section of NIOMR who worked on different aspects of this project.

\section{REFFRENCES}

Angliss RP, Outlaw RB. 2007. Alaska Marine Mammal Stock Assessments, 2006. NOAA Technical Memorandum NMFSAFSC-168. 244 pp.

Alcock J. 2005. Animal Behavior: An Evolutionary Approach $\left(1^{\text {st }}\right.$ edn). Sinauer Associates, Inc. Press: Sunderland, MA.

Bailey H, Thompson PM. 2006. Quantitative analysis of bottlenose dolphin movement patterns and their relationship with foraging. Journal of Animal Ecology, 75: 456-465.

Bejder L, Samuels A, Whitehead H, Gales N, Mann J, Connor R, Heithaus M, WatsonCapps J, Flaherty C, Krutzan M. 2006. Decline in relative abundance of bottlenose dolphins exposed to longterm disturbance. J. Conservation Biology, 20: 1791-1798.

Clark NM, Tetley MJ, Culloch RM, Mitchelson-Jacob EG, Robinson KP. 2006. Harbour porpoise (Phocoena phocoena) have declined in the southern outer Moray Firth, NE Scotland - a spatial and temporal view. European Research on Cetaceans 20 (on CD-ROM

Culik BM, Koschinski S, Tregenza N, Ellis G. 2001. Reactions of harbour porpoises (Phocoena phocoena) and herring (Clupea harengus) to acoustic alarms.
Marine Ecology Progress Series, 211: 255-260.

Gordon J, Gillespie D, Potter J, Frantzis A, Simmonds MP, Swift R, Thompson D. 2003. A review of the effects of seismic surveys on marine mammals. Marine Technology Society Journal, 37: 16-34.

JNCC. 2004. Guidelines for minimizing acoustic disturbance to marine mammals from seismic surveys. JNCC - Joint Nature Conservation Committee, Aberdeen, U.K.. http://www.jncc.gov. uk/pdf/Seismic_survey_guidelines_2004 04.pdf

JNCC. 2006. Guidelines for minimizing acoustic disturbance to marine mammals from seismic surveys. JNCC - Joint Nature Conservation Committee, Aberdeen, U.K. http://www.jncc.gov. uk/pdf/Seismic_survey_guidelines_2004 06.pdf.

Nachtigall LN, Gisiner PE, Breese R. 2010. Decreased echolocation performance following high-frequency hearing loss in the false Kloepper killer whale (Pseudorca crassidens). J. Exp. Biol., 213: 3717-3722.

Koblitz JC, Wahlberg M, Stilz P, Madsen P T, Beedholm K, Schnitzler HU. 2012. Asymmetry and dynamics of a narrow sonar beam in an echolocating harbor porpoise. J. Acoust. Soc. Am., 131: 23152324.

Kyhn LA, Jensen FH, Beedholm K, Tougaard J, Hansen M, Madsen PT. 2010. Echolocation in sympatric Peale's dolphins (Lagenorhynchus australis) and Commerson's dolphins (Cephalorhynchus commersonii) producing narrow-band high-frequency clicks. $J$. Exp. Biol., 213: 1940-1949.

Koschinski S, Culik BM, Henriksen OD, Tregenza N, Ellis G, Jansen C, Kathe G. 2003. Behavioral reactions of free- 
ranging porpoises and seals to the noise of a simulated $2 \mathrm{MW}$ windpower generator. Marine Ecology Progress Series, 265: 263-273.

Madsen PT, Kerr I, Payne R. 2004b. Echolocation clicks of two free ranging, oceanic delphinids with different food preferences: false killer whales Pseudorca crassidens and Risso's dolphins Grampus griseus. J. Exp. Biol. 207: 1811-1823.

Madsen PT, Johnson M, de Soto NA, Zimmer WMX, Tyack P. 2005. Biosonar performance of foraging beaked whales (Mesoplodon densirostris). J. Exp. Biol., 208: 181-194.

McCauley RD, Fewtrell J, Duncan AJ, Jenner C, Jenner M-N, Penrose JD, Prince RIT, Adhitya A, Murdoch J, Mccabe K. 2000 - Marine seismic surveys: a study of environmental implications. APPEA Journal, 40: 692-708.

Morton AB, Symonds HK. 2002. Displacement of Orcinus orca (L.) by high amplitude sound in British Columbia, Canada. ICES Journal of Marine Science, 59: 71-80.

National Research Council of the National Academies. 2003. Ocean Noise and Marine Mammals. Committee on Potential Impacts of Ambient Noise in the Ocean on Marine Mammals, Ocean Studies Board, Division on Earth and Life Studies. National Academies Press: Washington D.C.

Richardson WJ, Greene CR, Malme CI, Thomson DH. 1995. Marine Mammals and Noise. Academic Press: San Diego; 322-423.

Robinson KP, Tetley MJ. 2007. Behavioural observations of foraging minke whales (Balaenoptera acutorostrata) in the outer Moray Firth, northeast Scotland. Journal of the Marine Biological Association of the United Kingdom, 87: 85-86. 